Commentary on Pseudohallucinations in an Adolescent: Considerations for Diagnosis and Treatment in the Case of "Kate"

\title{
What Do We Know About the Correlates and Underlying Causes of Auditory Hallucinations in Nonpsychotic Children and Adolescents, and What Are the Implications for Diagnosis and Treatment?
}

\author{
PETER MERTIN ${ }^{\mathrm{a}, \mathrm{b}}$
}

${ }^{a}$ Legal Services Commission, Adelaide, Australia

${ }^{\mathrm{b}}$ Correspondence regarding this article should be addressed to Peter Mertin, Legal Services Commission, 159

Gawler Place, Adelaide 5000, Australia

E-mail: peter.mertin@lsc.sa.gov.au

\begin{abstract}
The case study of "Kate” (Shapiro, Bussing, \& Nguyen, 2014) provides us with further clinical information in an intriguing and evolving area in mental health; that of auditory hallucinations in nonpsychotic children and adolescents. While there is increasing acceptance that such hallucinations are not an automatic diagnostic marker of psychosis, or that psychosis is an inevitable outcome, there is still much to be learned about this phenomenon. This commentary will provide an overview of what is known about the correlates and possible underlying mechanisms generating auditory hallucinations in populations of nonpsychotic children and adolescents. In addition, Kate's case study raises interesting implications for diagnosis and intervention strategies, not only for children/adolescents experiencing auditory hallucinations, but for the wider area of child and adolescent mental health.
\end{abstract}

Key words: auditory hallucinations; emotional stress; diagnoses; case study; clinical case study

\section{CORRELATES OF AUDITORY HALLUCINATIONS IN NONPSYCHOTIC CHILDREN AND ADOLESCENTS}

One of the best researched triggers implicated in the generation of auditory hallucinations (in the absence of other factors such as brain injury or drug use) is that of traumatic life experiences (de Leede-Smith \& Barkus, 2013). With specific reference to clinical populations of nonpsychotic children, the presence of auditory hallucinations has typically been associated with a range of life stresses and adversities resulting in significant levels of emotional distress. The family backgrounds of hallucinating children have been alluded to in earlier clinical literature (e.g., Burke, Del Beccaro \& McCauley, 1988; Kotsopoulos Kanigsberg, Cote \& Fiedorowicz, 
What Do We Know About the Correlates and Underlying Causes of

P. Mertin

Auditory Hallucinations in Nonpsychotic Children and Adolescents,

and What Are the Implications for Diagnosis and Treatment?

Pragmatic Case Studies in Psychotherapy, http://pcsp.libraries.rutgers.edu

Volume 10, Module 4, Article 4, pp. 287-296, 12-16-14 [copyright by author]

1987), with these authors reporting psychiatric pathology, alcoholism, and lack of parental supports as being amongst the range of family-based stresses impinging upon these children.

The family backgrounds of hallucinating children referred to therapeutic outpatient services were described in studies by Mertin and Hartwig (2004) and by Best and Mertin (2007). In the case of all 23 children, family backgrounds were characterized by substantial dysfunction and disruption, with many of the children having witnessed family violence. Histories of psychiatric disorders in family members, as well as parental alcoholism and drug use were additional sources of stress experienced by these children. The children in the Mertin and Hartwig (2004) study were given DSM-IV (APA, 1994) diagnoses ranging from Generalized Anxiety Disorder to Acute Stress Disorder and PTSD. The children in the Best and Mertin (2007) study were assessed using the Trauma Symptom Checklist for Children-Alternate Version (TSCC-A; Briere, 1996), with the majority of children being rated in the clinical range, particularly in the areas of anxiety and depression.

Studies by Romme and Escher (2006) as well as Bartels-Velthuis and colleagues (Bartels-Velthuis, van de Willige, Jenner, Wiersma \& van Os, 2012) have similarly found a strong association between traumatic experiences and daily life stresses and auditory hallucinations. Romme and Escher (2006), for example, reported that $86 \%$ of the children in their study had experienced one or more traumas around the time of the onset of the voices, while Bartels-Velthuis et al. (2012) found a strong association between traumatic experiences in a sample of 337 children and both incidence and persistence of auditory hallucinations. Traumatic events assessed for in the above studies included severe illness or death in a family member, parental divorce, and social difficulties/victimization at school.

There is thus consistent research evidence demonstrating an association between auditory hallucinations in non-psychotic children and significant levels of emotional distress. There is also supporting evidence from a number of follow-up studies (Bartels-Velthuis et al., 2012; Escher, Romme, Buiks, Delespaul \& Van Os, 2002), as well as clinical research (e.g., Mertin \& Hartwig, (2004), that these hallucinations tend to abate as levels of distress decrease. There is nevertheless a poor understanding of how emotional distress may precipitate hallucinations, and why some children experience hallucinations while others seem not to.

\section{PATHWAYS TO AUDITORY HALLUCINATIONS, AND SOME ASSOCIATED DIFFICULTIES}

As high levels of emotion have been implicated in triggering hallucinations, there has been some research conducted with non-clinical populations examining the relationship between emotion and its influence on cognitive processes (e.g., Allen, Freeman, McGuire, Garety, et al., 2005). While cognitive models suggest that auditory hallucinations arise from the misattribution of inner speech to an external source, Allen et al., (2005) found that it was the influence of high levels of emotion, particularly anxiety, on cognitive functioning that was implicated in triggering hallucinations. Some support for this position was offered by de Leede-Smith and Barkus (2013) who, observing the close association between auditory hallucinations and PTSD, suggested that 
What Do We Know About the Correlates and Underlying Causes of

P. Mertin

Auditory Hallucinations in Nonpsychotic Children and Adolescents,

and What Are the Implications for Diagnosis and Treatment?

Pragmatic Case Studies in Psychotherapy, http://pcsp.libraries.rutgers.edu

Volume 10, Module 4, Article 4, pp. 287-296, 12-16-14 [copyright by author]

trauma acting on the individual via intrusive thoughts and memories may result in hallucinations. More specifically, Hugdahl (2009) proposed that hallucinations represented bottom-up perceptual misrepresentations due to a failure of top-down (cortical/pre-frontal) inhibition as a consequence of high levels of emotional stress.

In similar vein, Mertin and O’Brien (2013) examined the results of their study within the framework of high levels of emotional arousal and the effects on reality monitoring. These authors assessed the association between high levels of anxiety, depression and trauma symptomatology, and the presence of hallucinations in a clinical group of children and young adolescents against matched controls, and found that the hallucinating children and adolescents had significantly higher mean anxiety, depression and, in particular, re-experiencing scores on the TSCC-A (Briere, 1996) than did the children and adolescents in the control group. Developments in the understanding of how the brain responds to perceived threat have shown that the center of emotional responses lies generally within the limbic system, and that with increased limbic arousal (e.g., as a consequence of anxiety), the focus of the brain's functioning begins to move from the cortical to the limbic (i.e., subcortical) area, making responses more emotionally based and less reasoned. The results of this study were therefore consistent with the hypothesis that, under conditions of increased limbic arousal, errors in reality monitoring are likely to increase as the ability to cognitively evaluate experiences-that is, as cortical functioning becomes more compromised-is correspondingly diminished. This, in turn, increases the likelihood that intrusive thoughts and memories, particularly if generated under heightened emotional arousal, may be misinterpreted as hallucinations.

The hypothesis of auditory hallucinations in nonpsychotic children being generated by failures in reality monitoring as a consequence of high emotional arousal is consistent with the strong correlation between hallucinations and high levels of emotional distress found in the lives of these children, and by the fact that the frequency and intensity of hallucinations tended to abate as the level of emotional distress decreased (e.g., Escher et al., 2002). The hypothesis is also consistent with the generally reported location of these voices as being inside the head-as opposed to being "broadcast" from, for example, the radio or television-although it fails to explain the presence in some children of a number of different voices, or voices of both genders.

In addition, the hypothesis provides no immediately apparent relationship between failures in reality monitoring and the content of the hallucinations themselves, although this is an area that has not been extensively explored. While few studies have provided specific details about the content of the hallucinations, except to comment generally that many of the voices were reported as being threatening and distressing (e.g., Best \& Mertin, 2007), there is some evidence that content may have some significance to the child's life circumstances. Famularo, Kinscherff and Fenton (1992), for example, found a strong association between auditory hallucinations and a history of maltreatment (more specifically, a diagnosis of PTSD), and reported that the hallucinations themselves seemed to be related to details of past traumatic events. Kotsopoulos et al. (1987) had earlier reported a similar finding in relation to their subject children; namely, that "the hallucinations were coherent, made sense, and in some children were congruent with their life experiences and circumstances” (p.379). 
P. Mertin

Auditory Hallucinations in Nonpsychotic Children and Adolescents,

and What Are the Implications for Diagnosis and Treatment?

Pragmatic Case Studies in Psychotherapy, http://pcsp.libraries.rutgers.edu

Volume 10, Module 4, Article 4, pp. 287-296, 12-16-14 [copyright by author]

It was also the conclusion of Edelsohn, Rabinovich and Portnoy (2003) that the content of the hallucinations was often relevant in understanding the underlying psychopathology in the child's life and, in a later paper, Edelsohn (2006) provided two case vignettes that highlighted such a link between the contents of the hallucinations presented and the child's stressful life experiences. It is intriguing that some 40 years earlier Wilking and Paoli (1996) had made similar observations with respect to their pediatric clinical patients in New York. These authors reported that "in child after child there seemed to be correspondence between the content of the hallucination, the realities of the external environment, the areas in which the specific conflicts took place, and the coping mechanisms at the disposal of the child” (p. 439). The findings reported in these few studies provide hints that the content of auditory hallucinations may have some diagnostic value, although more research is now needed to confirm whether attention to content has clinical utility.

\section{A NOTE ON TERMINOLOGY}

Despite the strong historical association between auditory hallucinations and mental illness, particularly psychosis, a range of research evidence has consistently indicated that experiencing hallucinations in childhood does not necessarily lead to a later psychiatric diagnosis. In an attempt to distinguish between hallucinations that are part of a clearly diagnosed psychotic condition from a nonpsychotic disorder, the concept of "pseudohallucination" has sometimes been employed. As discussed by van der Zwaard and Polak (2001), such a concept is not necessarily diagnostically useful as it has low construct validity and is clinically ambiguous, having been described in the literature in a number of ways. These authors advanced the concept of "nonpsychotic hallucinations," arguing that this concept has two advantages: firstly it avoids the denomination of pseudohallucinations as "unreal" or "less severe", and it breaks the automatic link between hallucinations and psychosis. (p.47).

This last point is important, in my view, as hallucinations experienced by subjects drawn from clinical populations of children and adolescents have generally been shown to be associated with only a minor risk for later psychiatric symptoms, at least in younger children. Further, some studies have reported significant discontinuance in experiencing hallucinations. Escher, Romme, Buiks, Delespaul and Van Os (2002), for example, reported a cumulative rate of discontinuation of $60 \%$ in 80 children followed over a three year period which seemed to be independent of whether or not the children received mental health care. In similar vein, BartelsVelthuis and colleagues (2012), reporting on a five-year follow-up study of 337 children, found a discontinuation rate of $27 \%$. On the basis of their findings over the five year period these authors concluded that the presence of auditory hallucinations in early childhood was mostly benign and transitory, although the experience of a range of social adversities was associated with persistence and severity of hallucinations, as well as with the onset of new hallucinations closer to puberty. Thus, whether using the term "nonpsychotic hallucinations" as favored by van der Zwaard and Polak (2001), or simply referring to "hallucinations in nonpsychotic children/adolescents," importantly, regardless of whether hallucinations are severe and/or persist into adolescence, there is no evidence that psychosis is an inevitable outcome. 
What Do We Know About the Correlates and Underlying Causes of

P. Mertin

Auditory Hallucinations in Nonpsychotic Children and Adolescents,

and What Are the Implications for Diagnosis and Treatment?

Pragmatic Case Studies in Psychotherapy, http://pcsp.libraries.rutgers.edu

Volume 10, Module 4, Article 4, pp. 287-296, 12-16-14 [copyright by author]

\section{IMPLICATIONS FOR DIAGNOSIS}

As the presence of auditory hallucinations is strongly associated in the literature with a range of comorbidities such as anxiety, depression, and behavior problems (e.g., BartelsVelthuis, et al., 2010; Dhossche, Ferdinand, van der Ende, Hofstra \& Verhulst, 2002; Mertin \& Hartwig, 2004), examples in outpatient services often present a complex picture of intertwined mental health problems. Such complex presentations tend not to fit neatly into existing medical or DSM diagnostic categories, and can result in diagnostic confusion and the potential for poor treatment outcomes for these children and adolescents. Kaufman and colleagues (Kaufman, Birmaher, Clayton, Retano \& Wongchaowart, 1997) had previously cautioned that, as there were no formal guidelines for the diagnosis of children with hallucinations, the accurate diagnosis of these children is not merely an academic endeavor, as the treatment implications of psychotic versus nonpsychotic conditions are quite disparate. Edelsohn et al. (2006) similarly warned that children presenting with hallucinations ran the risk of being misdiagnosed as having psychosis and being subjected to the inherent risks of treatment with antipsychotics, and pointed out that a mistaken diagnostic label of psychosis based on the presence of hallucinations alone will follow the child in his or her medical record, and will likely influence future evaluations and clinical decision-making. As if to underline the above, in their case study Shapiro et al. (2014) acknowledged that the patient Kate nearly received a diagnosis of schizophrenia, and stressed the importance of a careful exploration of the presenting symptoms as well as associated factors such as family dynamics, in order to arrive at an accurate diagnosis.

A potentially confounding feature of Kate's presentation was her development of delusional thinking. Like hallucinations, delusional thinking has traditionally been regarded as a diagnostic marker of psychosis and, similar to hallucinations, there has been little research into the area of delusional thinking in nonpsychotic children and adolescents. Altman and colleagues (Altman, Collins \& Mundy, 1997) looked at the prevalence and symptom correlates of hallucinations and delusions in 38 nonpsychotic adolescents from a residential treatment and day center. They found the experience of hallucinations was confirmed by $38 \%$ of the adolescents, and delusional thinking by $24 \%$, although only four of the participants confirmed experiencing both hallucinations and delusional thought processes. An analysis of the results indicated that hallucinations seemed to be correlated with dissociative and depressive symptoms, whereas delusional symptoms were related more to "schizotypal thought processes" (p.418), leading the authors to speculate that hallucinations and delusions may reflect partially independent psychological processes.

More recently, however, there has been some evidence to support the view that delusions in nonpsychotic children may occur as a consequence of the high levels of anxiety associated with hallucinations, and which are therefore secondary to the hallucinations themselves (BartelsVelthuis et al., 2012; van der Zwaard \& Polak, 2001). Noting the strong associations between traumatic experiences and both the incidence and persistence of hallucinations, Bartels-Velthuis et al. (2012) reasoned that exposure to stressful childhood adversity increases the intrusiveness of the hallucinatory experience (and hence subjective distress), which in turn may increase the risk for secondary delusional ideation. While it is probably too early to determine the clinical 
What Do We Know About the Correlates and Underlying Causes of

P. Mertin

Auditory Hallucinations in Nonpsychotic Children and Adolescents,

and What Are the Implications for Diagnosis and Treatment?

Pragmatic Case Studies in Psychotherapy, http://pcsp.libraries.rutgers.edu

Volume 10, Module 4, Article 4, pp. 287-296, 12-16-14 [copyright by author]

relevance of secondary delusional formation, at least in terms of prognosis_-although the little evidence available would suggest a greater risk of transition to more serious psychopathologyit would seem of diagnostic importance to attempt to determine whether delusional ideation occurring in child or adolescent patients is secondary to the distress associated with experiencing hallucinations, or whether the delusional ideation represents a genuine thought disorder associated more with a psychotic condition.

As mentioned above, presentations to child and adolescent mental health facilities are invariably complex, encompassing emotional and behavioral dimensions, and often maintained by maladaptive coping strategies. In an attempt to resolve diagnostic confusions, children can end up being given a number of diagnoses which, at best, describe rather than explain the child's condition, and don't necessarily clarify treatment options. Diagnoses also tend to focus on the child per se, whereas what are defined as mental health problems in children are frequently a consequence of dysfunctional and/or abusive family dynamics. In relation to Shapiro et al.'s case of Kate, therefore, what was of greater clinical utility than arriving at a diagnosis - although eliminating a diagnosis of schizophrenia was important - was, in my view, the authors' formulation of the family's dynamics. The family history, describing the parents' own difficulties and their infantilizing of Kate, and the effects on Kate as she struggled for greater autonomy in adolescence, placed Kate's presentation within a more understandable context.

Within this formulation it is possible to understand the enmeshed relationships and suppressed emotional life that were central to the functioning of this family. It is possible to understand, too, Kate's internal conflicts, particularly the reasons for her anger and guilt, and the emotional distress engendered by this. As a consequence of this emotional distress Kate presented with a number of symptoms, including auditory hallucinations. While diagnoses of Depressive Disorder NOS and GAD were eventually confirmed, a diagnosis of schizophrenia would have resulted in a different treatment plan, and one that would not have addressed the issues underlying her presentation. The evidence arising from the family history together with the case formulation, however, made apparent the need for the parents to be included in the therapeutic process, as it was the family dynamics that were both the precipitating and perpetuating factors in Kate's presentation. In addition, Kate herself was also offered individual therapy in order to assist her in the better management of her hallucinations and her emotions more generally.

I found it interesting that the authors reported that it was the consideration of "pseudohallucinations" as conversion disorder symptoms that was the key to making an accurate diagnosis, and tailoring a treatment plan for Kate and her parents. Conversion disorders commonly refer to a condition where emotional distress is "converted" into physical symptoms, and where the symptoms cannot be fully explained medically. Feinstein (2011) considered that a conversion disorder had to consist of three components: the conversion of emotional arousal to physical symptoms (primary gain), certain benefits derived as a result of having symptoms (secondary gain), and the fact that the symptoms are not deliberately or consciously produced. On the basis of the authors' psychodynamic formulation of Kate's hallucinations (Shapiro et al., 2014. p. 11-12), the hallucinations could reasonably be interpreted within the framework of a 
P. Mertin

Auditory Hallucinations in Nonpsychotic Children and Adolescents,

and What Are the Implications for Diagnosis and Treatment?

Pragmatic Case Studies in Psychotherapy, http://pcsp.libraries.rutgers.edu

Volume 10, Module 4, Article 4, pp. 287-296, 12-16-14 [copyright by author]

conversion disorder and as therefore serving a stress-relieving function for Kate. As a related issue regarding the content of hallucinations, viewing the hallucinations as a conversion symptom raises the issue of what further clinical clarity may be gained in the interpretation of their "meaning," above and beyond the information elicited by a thorough psychiatric history. While this may be an issue for individual clinicians, such an approach also has the potential to muddy the waters in an area that, I suspect, is still poorly understood in the wider mental health community. There is also the danger of making diagnostic considerations too hallucinatorycentric, as the fact remained that Kate presented with a range of symptoms, including those of anxiety, anger, and depression, all of which were integral to her condition.

There remains the problem of how to view auditory hallucinations in children and adolescents, however. de Leede-Smith and Barkus (2013) were clear in their view that auditory hallucinations should no longer be recognized as a diagnostic indicator as the presence of such hallucinations is not intrinsically related to the outcome of the individual. Schreier (1998) considered that prognosis was likely to be more related to aspects of the child's condition rather than to the fact that they heard voices and, in a later paper (Schreier, 1999), advised that hallucinations seen in children needed to be regarded in the context of the rest of the clinical picture. The fact that auditory hallucinations are not confined to any single type of problem or diagnostic category, but can be present in a range of mental health problems (e.g., BartelsVelthuis, et al., 2010; Dhossche, et al., 2002; Mertin \& Hartwig, 2004), suggests that it may be most clinically practical, once having eliminated the presence of a psychotic condition, to simply regard them as symptoms of high levels of emotional stress in the child and, as suggested by Schreier (1999), to place them in context with the rest of the clinical picture. Why some children experience auditory hallucinations while others who present with similar conditions do not, remains largely unexplained. However, it may be, as suggested by Mertin and O’Brien (2013), that hallucinating children are simply more vulnerable to adverse effects of high stress levels, or have poorer coping strategies (e.g., Kotsopoulos et al., 1987), than those children who do not hallucinate.

\section{CONCLUSIONS}

Shapiro et al.'s case study of Kate has provided us with further clinical information in the area of auditory hallucinations in a nonpsychotic adolescent, and has also afforded us the opportunity to compare her case with what has so far been reported in the literature in this area. The literature is in general agreement that there is a strong association between hallucinations and high levels of emotional stress and that, while hallucinations tend to abate as levels of stress decrease, at least in younger children, there is also some evidence pointing to a poorer outcome in adolescence if the hallucinations persist. These features were certainly present in Kate's case and, although the hallucinations did eventually abate to the point where she was able to manage them without apparent distress, it took some two years of therapy with both Kate and her parents, in order to get to this point. At this point her prognosis is uncertain, and it should be noted that she may remain vulnerable to further stresses in her late adolescence. 
P. Mertin

Auditory Hallucinations in Nonpsychotic Children and Adolescents,

and What Are the Implications for Diagnosis and Treatment?

Pragmatic Case Studies in Psychotherapy, http://pcsp.libraries.rutgers.edu

Volume 10, Module 4, Article 4, pp. 287-296, 12-16-14 [copyright by author]

The authors acknowledged some strengths in Kate that assisted the therapeutic process, including the fact that Kate was cognitively intelligent and had good insight, and that both Kate and the parents were committed to continuing with therapy. Although the parents were reported as being able to make some gains in their emotional functioning over this period, Kate's move away to college may have also been particularly important as it reduced the source of stress in relating to her own emotions, and also represented a significant step in her development of autonomy.

Shapiro et al.'s case of Kate argues both for further research investigating the role of family dynamics in either the maintenance and/or resolution of hallucinations in children and adolescents, and for further research into the phenomenon of delusional thinking secondary to the presence of hallucinations. On the other hand, even without this future research and consistent with the present research evidence (e.g., Schreier, 1999), Shapiro et al. offer an outstanding example of how to place Kate's auditory hallucinations in the context of the entire clinical picture and how to develop and implement a treatment plan that addresses with considerable success the broad range of underlying issues in patients like Kate.

\section{REFERENCES}

Allen, P., Freeman, D., McGuire, P., Garety, P. et al. (2005). The prediction of hallucinatory predisposition in non-clinical individuals: examining the contribution of emotion and reasoning. British Journal of Clinical Psychology, 44, 127-132.

Altman, H., Collins, M. \& Mundy, P. (1997). Subclinical hallucinations and delusions in nonpsychotic adolescents. Journal of Child Psychology and Psychiatry, 38, 413-420.

Askenazy, F., Lestidea, K., Meyandier, A., Dor, E., Myquel, M. \& Lecrubier, Y. (2007). Auditory hallucinations in pre-pubertal children. A one-year follow-up, preliminary findings. European Child \& Adolescent Psychiatry, 16, 411-415.

Bartels-Velthuis, A., Jenner, J., van de Willige, G., van Os, J. \& Wiersma, D. (2010). Prevalence and correlates of auditory vocal hallucinations in middle childhood. British Journal of Psychiatry, 196, 41-46.

Bartels-Velthuis, A., van de Willige, , G., Jenner, , J. Wiersma, D. \& van Os, J. (2012). Auditory hallucinations in childhood: Associations with adversity and delusional ideation. Psychological Medicine, 42, 583-593.

Best, N. \& Mertin, P. (2007). Correlates of auditory hallucinations in nonpsychotic children. Clinical Child Psychology and Psychiatry, 12, 611-623.

Briere, J. (1996). Trauma Symptom Checklist for Children: Professional Manual. Tampa, FL. Psychological Assessment resources.

Burke, P., Del Beccaro, M., McCauley, E. \& Clark, C. (1985). Hallucinations in children. Journal of the American Academy of Child Psychiatry, 24, 71-75.

Dhossche, D., Ferdinand, R., van der Ende, J., Hofstra, M. \& Verhulst, F. (2002). Diagnostic outcome of self-reported hallucinations in a community sample of adolescents. Psychological Medicine, 32, 619-627. 
What Do We Know About the Correlates and Underlying Causes of

P. Mertin

Auditory Hallucinations in Nonpsychotic Children and Adolescents,

and What Are the Implications for Diagnosis and Treatment?

Pragmatic Case Studies in Psychotherapy, http://pcsp.libraries.rutgers.edu

Volume 10, Module 4, Article 4, pp. 287-296, 12-16-14 [copyright by author]

de Leede-Smith, S. \& Barkus, E. (2013). A comprehensive review of auditory verbal hallucinations: lifetime prevalence, correlates and mechanisms in healthy and clinical individuals. Frontiers in Human Neuroscience, 7, 367-411.

Edelsohn, G. (2006). Hallucinations in children and adolescents: Considerations in the emergency setting. American Journal of Psychiatry, 163, 781-785.

Edelsohn, G., Rabinovich, H. \& Portnoy, R. (2003). Hallucinations in nonpsychotic children. Findings from a psychiatric emergency service. Annals New York Academy of Science, 1008, 261-264.

Escher, S., Romme, M., Buiks, A., Delespaul, P. \& van Os, J. (2002). Independent course of childhood auditory hallucinations: A sequential 3-year follow-up study. British Journal of Psychiatry, 181, 10-18.

Famularo, R., Kinscherff, R. \& Fenton, T. (1992). Psychiatric diagnoses of maltreated children: Preliminary findings. Journal of the American Academy of Child and Adolescent Psychiatry, 31, 863-867.

Feinstein, A. (2011). Conversion disorder: Advances in out understanding. Canadian Medical Association Journal, 183, 915-920.

Hugdahl, K. (2009). “Hearing Voices”. Auditory hallucinations as failure of the top-down control of bottom-up perceptual processes. Scandinavian Journal of Psychology, 50, 553-560.

Kaufman, J., Birmaher, B., Clayton, S., Retano, A. \& Wongchaowart, B. (1997). Case study: trauma-related hallucinations. Journal of the American Academy of Child and Adolescent Psychiatry, 36, 1602-1605.

Kotsopoulos, S., Kanigsberg, J., Cote, A. \& Fiedorowicz, C. (1987). Hallucinatory experiences in nonpsychotic children. Journal of the American Academy of Child and Adolescent Psychiatry, 26, 375-380.

Mertin, P. \& Hartwig, S. (2004). Auditory hallucinations in nonpsychotic children: Diagnostic considerations. Child and Adolescent Mental Health, 9, 9-14.

Mertin, P. \& O’Brien, N. (2013). High emotional arousal and failures in reality monitoring: Pathways to auditory hallucinations in non-psychotic children? Scandinavian Journal of Psychology, 54, 102-106.

Romme, M. \& Escher, S. (2006). Trauma and hearing voices. In W. Larkin \& A. Morrison (Eds). Trauma and psychosis. New directions for theory and therapy. (pp.162-191). London: Routledge.

Schreier, H. (1998). Auditory hallucinations in nonpsychotic children with affective syndromes and migraines: Report of 13 cases. Journal of Child Neurology, 13, 377-382.

Schreier, H. (1999). Hallucinations in nonpsychotic children: More common than we think? Journal of the American Academy of Child and Adolescent Psychiatry, 38, 623-625.

Shapiro, M.A., Bussing, R., \& Nguyen, M.L. (2014). Pseudohallucinations in an adolescent: Considerations for diagnosis and treatment in the case of "Kate." Pragmatic Case Studies in Psychotherapy, 10(4), Article 1, 227-259. Available: http://hdl.rutgers.edu/1782.1/pcsp_journal.

Wilking, V. \& PaoIi, C. (1966). The hallucinatory experience. An attempt at a psychodynamic classification and reconsideration of its diagnostic significance. Journal of the American Academy of Child Psychiatry, 5, 431-440. 
What Do We Know About the Correlates and Underlying Causes of

Auditory Hallucinations in Nonpsychotic Children and Adolescents,

P. Mertin and What Are the Implications for Diagnosis and Treatment?

Pragmatic Case Studies in Psychotherapy, http://pcsp.libraries.rutgers.edu

Volume 10, Module 4, Article 4, pp. 287-296, 12-16-14 [copyright by author]

van der Zwaard, R. \& Polak, M. (2001). Pseudohallucinations: A pseudoconcept? A review of the validity of the concept, related to associated symptomatology. Comprehensive Psychiatry, 42, 42-50. 